\title{
Automatic and voluntary focusing of attention
}

\author{
MASSIMO TURATTO, FRANCESCO BENSO, ANDREA FACOETTI, \\ GIOVANNI GALFANO, GIAN GASTONE MASCETTI, and CARLO UMILTÀ \\ University of Padua, Padua, Italy
}

\begin{abstract}
In this study, we investigate whether attentional focusing, like attentional orienting, comprises two independent mechanisms. We provide direct empirical evidence in favor of the existence of two mechanisms - one exogenous, or automatic, and one endogenous, or voluntary-that play a role in adjusting the size of the focus of attention. When a new object suddenly occurs in the visual field, the focus is first automatically fitted to it, and then an endogenous effort has to be exerted to maintain attention in the focused mode. Also, we provide evidence that voluntary focusing needs a perceptual object in order to operate.
\end{abstract}

Turning the eyes and the head to an object when it suddenly appears in the visual field, producing what is called exploration behavior, is a common experience for everyone. Sokolov (1963) described this phenomenon as the orienting reflex. The purpose of the orienting reflex is to allow the central system to identify the new element that has just occurred in order to prepare the whole organism to react, if necessary, to it. This reflex is composed of a series of independent mechanisms, one of the most important of which is the orienting of attention to the region in space where the new element has appeared (see, e.g., Posner, Snyder, \& Davidson, 1980).

Usually, the movement of attention is accompanied by a movement of the eyes to foveate a specific area of the visual field, but as has been well established by many studies, a person can selectively attend to a region in space without making any eye movements (e.g., Eriksen \& Colegate, 1971; Eriksen \& Hoffman, 1972; Posner, 1980; Posner et al., 1980). When the focus of attention is correctly oriented, stimulus detection or discrimination is enhanced. This is what Posner (1980) named covert orienting.

However, because objects observed in everyday life have different shapes and sizes, it is plausible that once the focus of attention has been oriented, it will also be adjusted to the size of the attended figure. That is what we call the focusing process. The main aim of the present study was to provide evidence that focusing is a different process from orienting. Focusing was investigated in isolationthat is, in the absence of orienting, which, in contrast, was involved in all of the previous studies on focusing.

The research was supported by grants from CNR and MURST to G.G.M. and C.U. The authors thank Stefania Taleschi and Barbara Bellini for their help in collecting the data and Sandro Bettella for technical support. We are grateful to Vincent Brown, Garvin Chastain, Roger Remington, Jan Theeuwes, Steven Yantis, and two anonymous reviewers for their very helpful comments on an early draft of this paper. Correspondence concerning this article should be addressed to C. Umiltà, Dipartimento di Psicologia Generale, Via Venezia, 8, 35131 Padova, Italy (e-mail: umilta@psico.unipd.it).

\section{STIMULUS-DRIVEN SHIFTS OF SPATIAL ATTENTION}

Posner (1980) and Jonides (1981) proposed two different sources of control for the movement of attention: (1) endogenous (or voluntary) orienting, determined and controlled by the subject's will, and (2) exogenous (reflexive or nonvoluntary) orienting, usually out of the subject's control and determined by the abrupt onset of a peripheral stimulus.

It is not easy, however, to establish when a process should be considered automatic. Often a process is thought to be automatic only if it satisfies two criteria: (1) the load-insensitivity criterion, meaning that an automatic process is insensitive to the current task demands, and (2) the intentionality criterion, meaning that an automatic process is not under the subject's voluntary control (see, e.g., Hasher \& Zacks, 1979; Posner \& Snyder, 1975; Schneider \& Shiffrin, 1977).

A first series of studies about the automatic orienting of attention (e.g., Jonides, 1981; Jonides \& Yantis, 1988; Müller \& Rabbitt, 1989; Yantis \& Jonides, 1984) led to the conclusion that the abrupt onset of a peripheral stimulus captures attention automatically. However, in more recent studies, Yantis and Jonides (1990) and Warner, Juola, and Koshino (1990) demonstrated that such attentional capture is not fully automatic but, rather, is only partially automatic. In fact, although it often meets the loadinsensitivity criterion, it does not completely satisfy the intentionality criterion, because, when the visual system is in a focused attention mode, an abrupt onset does not capture attention.

In a series of more recent studies, it has been further investigated how the features of a stimulus (i.e., abrupt visual onset, color, form, movement, and luminance) can capture attention in a stimulus-driven fashion (e.g., Folk, Remington, \& Johnston, 1992; Folk, Remington, \& Wright, 1994; Johnson \& Yantis, 1995; Martin \& Benson, 1991; Theeuwes, 1991, 1994; Yantis \& Hillstrom, 1994). Abrupt visual onset showed a specific strength in 
summoning attention, and two possible mechanisms seem to be able to explain this phenomenon-that is, a luminance-change detection system and a new-object detection system.

According to the luminance-change hypothesis, an abrupt onset generates a luminance increment that is detected by the visual system, which interprets this phenomenon as a signal that an interesting event has occurred in that spatial location and then directs attention there (Breitmeyer \& Ganz, 1976; Todd \& Van Gelder, 1979; Yantis \& Jonides, 1984).

The alternative account claims that attention is not attracted by luminance increments, but by the object per se. In other words, in accordance with object-based theories, the appearance of a new object in the visual scene is able to capture attention, creating an object file to represent the features of the perceptual element (Duncan, 1984; Kahneman \& Treisman, 1984; Kahneman, Treisman, \& Gibbs, 1992; Kanwisher \& Driver, 1992; Yantis \& Hillstrom, 1994). The Yantis and Hillstrom study provided especially clear evidence in favor of the new-object explanation, showing that the occurrence of an equiluminant visual object captures attention, whereas a simple luminance increment alone is not sufficient to capture attention.

\section{FOCUSING OF ATTENTION}

Whereas the majority of the studies in which spatial attention was investigated were dedicated to exploring how attention moves in the visual field, other studies were concerned with the capability of varying the spatial extent of the attentional focus (e.g., Benso, Turatto, Mascetti, \& Umiltà, 1998; Castiello \& Umiltà, 1990, 1992; Egeth, 1977; Eriksen \& St. James, 1986; Eriksen \& Yeh, 1985; Henderson, 1991; LaBerge, 1983; LaBerge \& Brown, 1986).

In particular, from the studies of Eriksen and Yeh (1985) and Eriksen and St. James (1986; see also Wundt, 1903), the zoom lens metaphor emerged. It states that the focus size can change and that, consequently, the concentration of the attentional resources allocated to a given area can be modified. Particularly important is the prediction of an inverse relation between the extent of the focus and the efficiency of processing within its borders. That is, in processing a visual stimulus, concentration of attentional resources inside a small cue (e.g., a box delimiting an area in the visual field) should lead to faster reaction time (RT) than does concentration inside a large cue. This is called the cue size effect, and several studies, using different tasks (e.g., single-item detection, recognition, or discrimination tasks), have supported it (Benso et al., 1998; Castiello \& Umiltà, 1990, 1992; Eriksen \& St. James, 1986; Eriksen \& Yeh, 1985; Maringelli \& Umiltà, 1998; Mizuno, Umiltà, \& Sartori, 1998).

Accordingly, we suggest that after attention has been oriented to an object, another, independent process- namely, focusing - is activated, which makes the attentional focus fit the object's size. Focusing has seldom been recognized as independent from orienting; rather, the two processes have been confounded. However, some evidence emerging from early works (Castiello \& Umiltà, 1990; Stoffer, 1991) suggests that focusing and orienting might be separate processes. First, Castiello and Umiltà (1990) showed that when subjects had to orient and focus attention to a peripheral box (which could be small or large), with a $40-50 \mathrm{msec}$ stimulus onset asynchrony (SOA), the cue size effect did not take place, whereas benefits for a correct orienting were observed. By contrast, with a 500-msec SOA, a reliable cue size effect was also obtained. As the authors suggested, it is possible that at the shortest SOA, the process of narrowing the attentional focus had not yet been terminated, whereas orienting had, at least in part, already occurred. Second, Stoffer (1991; see also Stoffer \& Umiltà, 1997) found that a spatial compatibility effect was caused by the orienting of attention, but not by the zooming process. The author argued that the positional code of the stimulus is crucial for orienting but is immaterial for zooming.

By presenting the stimuli (i.e., the cue and the target) always in the same position in the center of the screen, Maringelli and Umiltà (1998) made a first attempt to study focusing in isolation from orienting. They found that focusing - that is, a cue size effect - occurred with an SOA of $100 \mathrm{msec}$. Also, they showed that focusing occurred when the size of the target object changed randomly from trial to trial, but not when blocks of objects of the same size were presented. This was taken as evidence that focusing is automatically triggered by the appearance of a new object. However, the differential effects of random and blocked presentations do not represent direct evidence of the automatic nature of focusing, because mixed and blocked presentations seem to affect the orienting of attention in different ways. Posner (1978) showed that when two different target eccentricities were randomly presented in a series of trials, benefits in the orienting of attention were related to the level of eccentricity, whereas with eccentricity blocked, identical benefits were found at all of the eccentricities tested. Similarly, Hawkins, Shafto, and Richardson (1988) found that the speed of response was related to target luminance when the level of luminance varied within blocks, whereas this effect disappeared when the level of luminance varied between blocks. It is likely that the differential effects of random and blocked presentations reflect the intervention of a strategic component in the control of attentional focusing, rather than the automatic mechanism per se.

Benso et al. (1998) investigated the time course of focusing, and suggested that focusing might be composed of two stages: an earlier stage, during which the focus of attention is automatically triggered by the abrupt onset of the new object, and a later stage, during which the size of attentional focus is maintained in a controlled, volun- 
tary manner. That is, they suggested that, similar to orienting, focusing depends on two separate mechanisms, one voluntary and the other automatic.

Note that, in the case of orienting, the two processes can be simultaneously active. ${ }^{1}$ This happens when the subject is instructed to direct attention to a stimulus that suddenly appears in the periphery of the visual field. The peripheral stimulus automatically captures attention, but the subject also voluntarily directs attention to it. In contrast, we believe that automatic focusing precedes voluntary focusing. When an object suddenly appears, the focus of attention automatically fits its size. After some time, however, automatic focusing ceases, and there is a tendency to switch from the focal to the diffuse mode. To counteract this tendency, focusing must be voluntarily maintained.

In sum, previous studies have merely hypothesized (Benso et al., 1998) or provided only indirect evidence for (Maringelli \& Umiltà, 1998) the existence of two different focusing mechanisms. Thus, in the present study, we sought to address this issue in a conclusive way by trying to provide, for the first time, clear and direct evidence on the automatic and voluntary focusing mechanisms. (For the orienting of attention, the dichotomy of automatic versus controlled has already been extensively investigated; see, e.g., Henderson \& Macquistan, 1993; Jonides, 1981; Müller \& Rabbitt, 1989; Riggio \& Kirsner, 1997; Umiltà, Riggio, Dascola, \& Rizzolatti, 1991.)

Experiments 1 and 2 of the present study dealt with the voluntary component of focusing, whereas Experiments 3 and 4 dealt with the automatic component. The whole set of experiments was based on the notion that an inverse relation between speed of processing (i.e., RT) and cue size indexes control of the attentional focus. That is, given two cue sizes, effective focusing can be assumed to have occurred when the RT to the stimulus is faster when it is inside the smaller cue than when it is inside the larger cue (Benso et al., 1998; Castiello \& Umiltà, 1990, 1992; Eriksen \& St. James, 1986; Eriksen \& Yeh, 1985; Maringelli \& Umiltà, 1998; Mizuno et al., 1998).

Experiments 1 and 3 were based on a simple detection task, even though, for the study of attention, paradigms based on simple RT tasks are sometimes considered to be less informative than those that rely on target discrimination. In our view, this is not always true, and which experimental task is chosen should depend on what aspect of attention is being studied. One aspect of attention is selection of spatial position (the where process); the other is selection of identity information-that is, object features (the what process). The distinction between these two different types of attention has a long tradition in psychology. For example, whereas "Von Helmoltz's central attention is characterized in terms of 'the where', i.e., in terms of position or spatial location, ... James's central attention is mainly defined in terms of 'the what', i.e., the identity or meaning" (van der Heijden, 1992, pp. 37-38).
In the past 10 years, research was particularly devoted to investigating, by means of visual search tasks, how attention can be summoned by stimulus properties (e.g., color, form, orientation, etc.). In this kind of paradigm, based on target discrimination, subjects usually are presented with multielement displays and are told to identify which of two possible targets (e.g., the letter $\mathrm{E}$ or $\mathrm{H}$ ) among distractors (e.g., other letters that may or may not be different in color from the target) is present. This way, by presenting multielement displays, the selective function of attention, understood as the process of picking up some features of the stimulus (such as its color and/or orientation), is fully addressed. From this standpoint, a target discrimination task is probably the most profitable task one can use to investigate the process of attentional selection. On the other hand, if the selection is only with regard to spatial position, a simple detection task in an uncluttered display can be perfectly suitable for investigating the orienting of attention, as Posner et al. (1980; see also Posner, Nissen, \& Ogden, 1978) have well demonstrated. If control of the width of the attentional focus is a component of the spatial selection process, a simple RT task can address the issue successfully (Benso et al., 1998; Castiello \& Umiltà, 1990, 1992; Maringelli \& Umiltà, 1998; Mizuno et al., 1998). In addition, by means of a simple RT task, it is possible to investigate the focus of attention without considering other attentional factors, such as expectation and intention, necessarily involved in a choice RT task (see, e.g., van der Heijden, 1992). However, Experiments 2 and 4 provided evidence that the cue size effect can also be obtained with a target discrimination task.

In conclusion, the aim of the present study was to obtain evidence that focusing is different from orienting and to investigate the automatic and the voluntary components of focusing when isolated from orienting, which, in contrast, is the main issue in spatial attention studies.

\section{EXPERIMENT 1}

Usually, the sudden appearance of an object in the visual field summons attention to its location. We suggest that, once orienting has been completed, focusing is initiated. As was mentioned before, focusing, like orienting, may be governed by two distinct mechanisms - one automatic, for short intervals (about $100 \mathrm{msec}$ ), and one voluntary, for longer intervals. We are presently interested in exploring the voluntary component, which presumably allows subjects to keep the focus of attention adapted to the object size. To investigate the endogenous component, subjects performed a task requiring detection of a small dot presented at the center of a circle cue, which could be of two possible sizes (small or large). The interval between cue onset and target onset was fixed at $804 \mathrm{msec}$ $(50$ refresh at $60 \mathrm{~Hz}$ ) in order to exclude any automatic component from the process being investigated.

A precue procedure was used, which allowed the subject to orient attention before cue presentation. As has 
been discussed in Benso et al. (1998), this procedure has the advantage of unconfounding focusing from orienting when the cue is presented in the periphery of the screen.

\section{Method}

Subjects. Twenty-four students at the University of Padua ( 12 males and 12 females), all right-handed and with normal or corrected-to-normal vision, served as subjects. They were not aware of the purpose of the experiment.

Apparatus and Procedure. The experiment took place in a dimly lit room. The subjects sat in front of a 19-in. monitor, with the head positioned on a headrest, so that the distance between the eyes and the screen was about $40 \mathrm{~cm}$. The precue, the cue, and the imperative stimulus were provided by a Digital Venturis 575 personal computer. They had a luminance of $24 \mathrm{~cd} / \mathrm{m}^{2}$, whereas the screen luminance was $0.5 \mathrm{~cd} / \mathrm{m}^{2}$. The precue and the imperative stimulus were green and white dots, respectively, and subtended $0.5^{\circ}$ of visual angle. The cue was a white circle of $2.5^{\circ}$ or $7.5^{\circ}$ (diameter).

At the beginning of the trial, the precue (the green dot) was flashed for $250 \mathrm{msec}$ on the screen, accompanied by a $2000-\mathrm{Hz}$ tone. Its spatial position changed randomly from one trial to the next. Then, the precue was turned off, and after an interval of $150 \mathrm{msec}$, the cue (the white circle) was presented at the same location on the screen as the precue. After an 804-msec SOA, the imperative stimulus (the white dot) was flashed for $200 \mathrm{msec}$ at the center of the cue (see Figure 1). Then, the cue remained on until the end of the trial.

At stimulus onset, the subject had to press the space bar on the keyboard as quickly as possible, and the RT was recorded by the computer. The maximum time allowed for the response was $1 \mathrm{sec}$. Catch trials, consisting of the presentation of the cue, but not of the stimulus, were intermingled with regular trials. On catch trials, the subject did not have to respond. The total number of trials was 92 , divided into two blocks of 46 trials. Each block consisted of 40 regular trials and 6 catch trials (about $13 \%$ of the total trials).

\section{Results}

In this and all the subsequent experiments, outliers were removed from the data sets before the analyses were carried out. Outliers were defined as RTs faster than $150 \mathrm{msec}$ or slower than 2.5 standard deviations above the mean. This latency criterion removed fewer than $1.5 \%$ of all the observations. Errors - that is, responses on catch trials-were fewer than $2 \%$ and were not analyzed.

An analysis of variance (ANOVA) was performed on RTs. The only factor, cue size, was significant $[F(1,23)=$ $37.050, p<.001]$. RT was inversely related to the size of the cue (small cue, $M=293 \mathrm{msec}, S D=31$; large cue, $M=306 \mathrm{msec}, S D=32$ ).

\section{Discussion}

The results confirmed the inverse relation between size of the cue and speed of processing, which was predicted on the basis of the zoom lens metaphor (Eriksen \& St. James, 1986; see also Wundt, 1903) and had already been shown in several previous studies (Benso et al., 1998; Castiello \& Umiltà, 1990, 1992; Maringelli \& Umiltà, 1998; Mizuno et al., 1998).

The experiment clearly showed that target detection was faster when the target was presented inside the small cue than when it appeared inside the large cue. As would be predicted on the basis of the zoom lens metaphor, the small cue benefits from more concentrated attentional resources, thus producing a faster response. An alternative explanation might be based on objective location uncertainty. The larger cue may require exploration of a wider area for target detection, and that may produce slower RTs. However, this explanation can be ruled out, because the onset target occurred in the same location (the center of the circle) on all the trials, regardless of cue size. Another possible nonattentional account for the cue size effect would state that is more difficult to estimate the precise center of a large cue than that of a small cue. This account will be discarded on the basis of the results of Experiment 3.

The procedure we employed allowed us to exclude orienting, so that the only process investigated was the adjusting of the width of the focus to the object size-that is, what we termed the focusing of attention (e.g., Benso et al., 1998; Maringelli \& Umiltà, 1998; Mizuno et al., 1998). As was discussed in the introduction, we believe that focusing and orienting are two different and at least partially independent processes. However, studies have shown that a spatial shift of attention comprises three different processes: disengaging attention, moving attention toward the target position, and engaging attention on the new location (e.g., Posner \& Petersen, 1990; Posner, Walker, Friedrich, \& Rafal, 1987). Therefore, what we term focusing may in fact be equated with engaging: Once attention has moved to an object, it is also engaged and focused on the object. In this sense, focusing can be interpreted as part of orienting.

\section{EXPERIMENT 2}

The results of Experiment 1 showed that subjects were able to produce active focusing - that is, a reliable cue size effect - at an 804-msec SOA. However, because the stimulus was always presented at the center of the cue, the presence of the cue size effect seems to be counterintuitive. Why did the subjects not focus exactly on the target location? Why did the subjects not ignore the cue size, voluntarily narrowing their focus on the center of the cue? The answers to these questions are critical for the interpretation of the cue size effect at the 804-msec SOA as an attentional effect.

We suggest two possible explanations. The first states that although subjects knew in advance both the precise time and the position of stimulus presentation, they did not narrow the focus toward the center of the cue because, during voluntary focusing, the size of the focus cannot be changed. Therefore, when the cue appeared, the focus was automatically fitted to the cue size, and then the voluntary mechanism could only maintain that size. The second explanation states that the size of the focus can be changed during voluntary focusing, but only if another object is present. The results of Experiment 1 do not allow us to distinguish between these two possibilities, because 

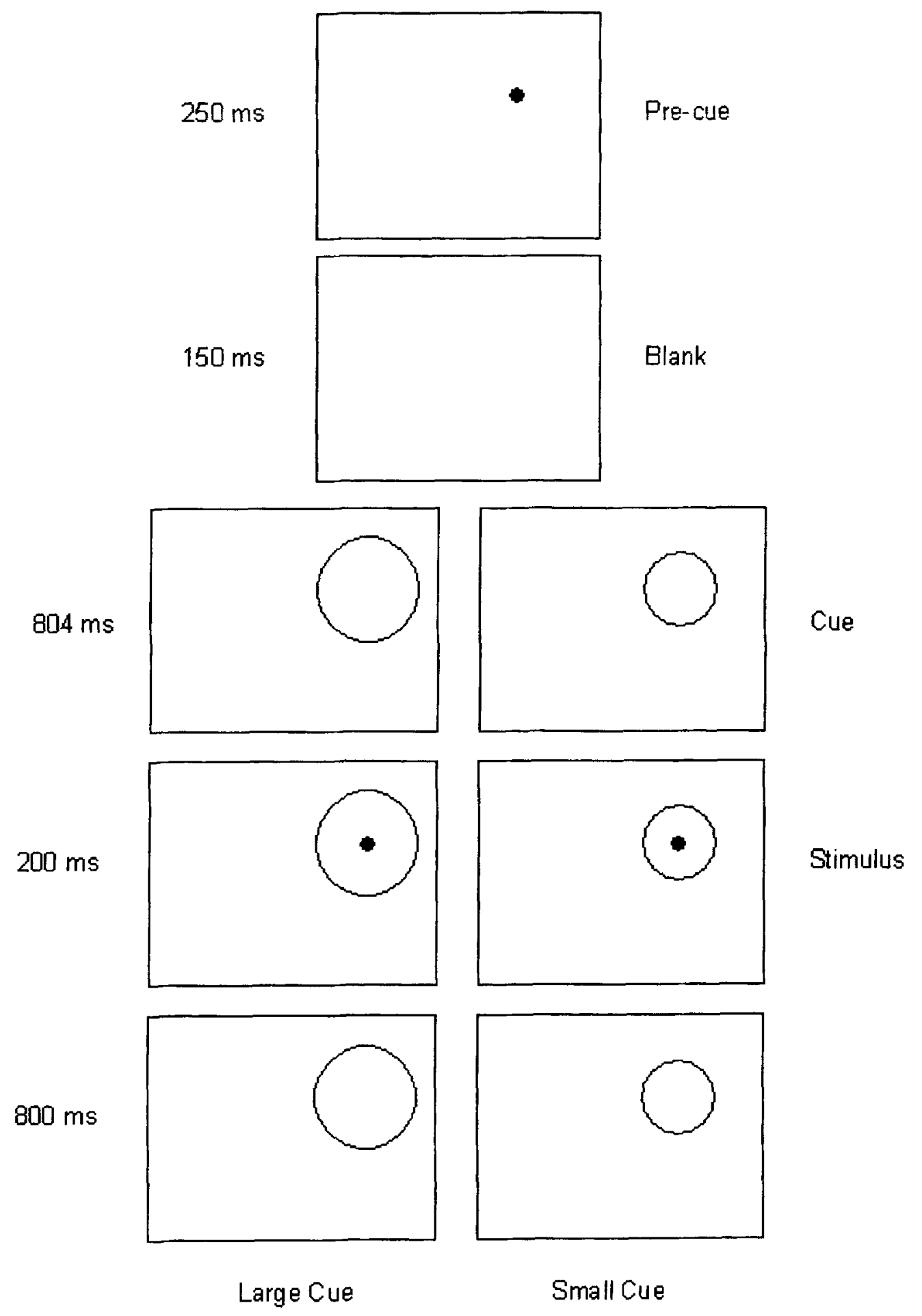

Figure 1. Schematic representation of the sequence of events in Experiment 1. The cues are not drawn to scale; the large cue was actually three times the size of the small cue.

only one cue was presented. Experiment 2 was planned to address this issue. In addition, a target discrimination task was used, in order to investigate whether the cue size effect can be obtained with this kind of task too.

An additional concern regards the possible effect in Experiment 1 of eye movements caused by the precue procedure. As we have already pointed out, the precue allowed us to estimate the time for focusing while excluding the time for orienting, even though the cue appeared off the center of the screen. The interval between the precue and the cue was $400 \mathrm{msec}$ (see Figure 1). It is very likely that, with such an interval, foveating had already 
been finished before the cue appeared and, therefore, no eye movements were necessary. No doubt, a much simpler way to isolate focusing from orienting would have been to present the cue at the center of the screen. However, this is not always the way the visual system operates. In fact, in everyday life, the objects of interest that summon attention do not always occur in the center of the visual field; rather, very often, eye movements are needed. Although we have already shown that when the precue is used the cue size effect is not affected by eye movements (Benso et al., 1998, Experiment 2), in Experiment 2 eye movements were eliminated by presenting the cue and the stimulus at the center of the screen, where the fixation point was also located.

\section{Method}

Subjects. Thirteen students at the University of Padua ( 6 males and 7 females), all right-handed and with normal or corrected-tonormal vision, served as subjects. They were not aware of the purpose of the experiment and had not taken part in Experiment 1.

Apparatus and Procedure. The apparatus was the same as that in the previous experiment. The cue was either a small green circle of $3^{\circ}$ of visual angle or a large red square of $8.5^{\circ}$ and had a luminance of $4 \mathrm{~cd} / \mathrm{m}^{2}$. The stimulus was a white $E$ on half of the trials and a white $\mathrm{H}$ on the other half and subtended $0.35^{\circ} \times 0.7^{\circ}$. The stimulus was always presented inside the small cue and around a fixation point on an imaginary circle whose radius was about $1.0^{\circ}$.

At the beginning of the trial, a fixation point $\left(0.1^{\circ}\right)$ was presented at the center of the screen and remained on until the end of the trial. Then, four different cue-target sequences were presented to every subject (see Figure 2).

Sequence A. After $500 \mathrm{msec}$ from onset of the fixation point, the small cue was presented for $500 \mathrm{msec}$. Then the large cue was displayed around the small cue and remained on for $804 \mathrm{msec}$. At the end of the SOA, the target was briefly flashed for $50 \mathrm{msec}$ around the fixation point.

Sequence B. After $500 \mathrm{msec}$ from onset of the fixation point, the large cue was presented for $500 \mathrm{msec}$. Then the small cue was displayed inside the large cue and remained on for $804 \mathrm{msec}$. At the end of the SOA, the target was briefly flashed for $50 \mathrm{msec}$ around the fixation point.

Sequence C. After $500 \mathrm{msec}$ from onset of the fixation point, the small cue was presented for $500 \mathrm{msec}$. Then the large cue was turned on, and the small cue was turned off. The large cue remained on for $804 \mathrm{msec}$. After the end of the SOA, the target was briefly flashed for $50 \mathrm{msec}$ around the fixation point.

Sequence D. After $500 \mathrm{msec}$ from onset of the fixation point, the large cue was presented for $500 \mathrm{msec}$. Then the small cue was turned on, and the large cue was turned off. The small cue remained on for $804 \mathrm{msec}$. After the end of the SOA, the target was briefly flashed for $50 \mathrm{msec}$ around the fixation point.

At stimulus onset, the subject had to press the appropriate response key (the $\mathrm{Q}$ key for the letter $\mathrm{H}$ and the $\mathrm{P}$ key for the letter $\mathrm{E}$ ) on the keyboard as quickly as possible, and the RT was recorded. The maximum time allowed for the response was $1 \mathrm{sec}$.

Each subject performed all four of the sequences, which were randomly presented within a block of trials. The total number of trials was 80 , divided into two blocks of 40 . The trials of each block were equally distributed among the four sequences. Before the experiment began, the subjects performed some training trials until they felt confident with the task. The subjects were also instructed to keep their eyes at fixation throughout the trial. In addition, eye movements were monitored on line by means of an infrared ray device throughout the trial. Those trials in which an eye movement was detected were discarded but not replaced.

\section{Results}

Errors, including eye movements, were fewer than $4 \%$ and were not analyzed. The data were entered into an ANOVA for repeated measures. The two factors considered were first cue (present or absent) and second-cue size (small or large). Both factors were significant [first cue, $F(1,12)=25.325, p<.001$, with subjects responding more rapidly when the first cue was still present at stimulus occurrence (present, $M=415 \mathrm{msec}, S D=25$; absent, $M=425 \mathrm{msec}, S D=27)$; second-cue size, $F(1,12)=$ $7.943, p<.02$, with subjects responding more rapidly when the second cue was small $(M=414 \mathrm{msec}, S D=24)$ than when it was large $(M=426 \mathrm{msec}, S D=28)]$. The first cue $\times$ second-cue size interaction was also significant $[F(1,12)=12.157, p<.005]$, showing that the cue size effect (for the second cue) was present only when the first cue was turned off (second cue large and first cue present, $M=417 \mathrm{msec}, S D=26$; second cue small and first cue present, $M=413 \mathrm{msec}, S D=23$; second cue large and first cue absent, $M=435 \mathrm{msec}, S D=27$; second cue small and first cue absent, $M=415 \mathrm{msec}, S D=25$; see also Figure 3). Newman-Keuls post hoc tests were applied to the data: The size of the second cue did not affect RTs for target discrimination when the first cue was present (n.s.), whereas RTs for target discrimination were significantly faster for the small cue than for the large cue when the first cue was absent $(p<.01)$.

\section{Discussion}

The aim of the present experiment was to explain why, in Experiment 1, the subjects did not focus on target position while disregarding the size of the cue. We suggested two hypotheses to explain why that did not happen. The first was that the voluntary mechanism can only maintain the size of the focus that was obtained by the automatic mechanism. The second hypothesis was that the voluntary mechanism can change the size of the focus only if another object is present.

The comparison between RTs in Sequence A (second cue large and first cue present) and RTs in Sequence B (second cue small and first cue present) is critical to the first hypothesis. In Sequence A, the small cue was presented first, and the large cue second; in Sequence B, the order was reversed (see Figure 2). It follows that, if the size of the focus cannot voluntarily be changed, RTs should be faster in Sequence B than in Sequence A, because the focus should maintain the size produced by the second cue. Contrary to this prediction, no RT difference emerged between Sequences A and B.

The comparison between RTs in Sequence C (second cue large and first cue absent) and RTs in Sequence D (second cue small and first cue absent) is critical to the second hypothesis. Sequences $C$ and $D$ were identical to Sequences A and B, respectively, except that the first cue was turned off when the second cue was presented (see Figure 2). If the extent of the focus can be changed only when another object is presented, the presence of a single cue should make the change of the focus impossible, thus 

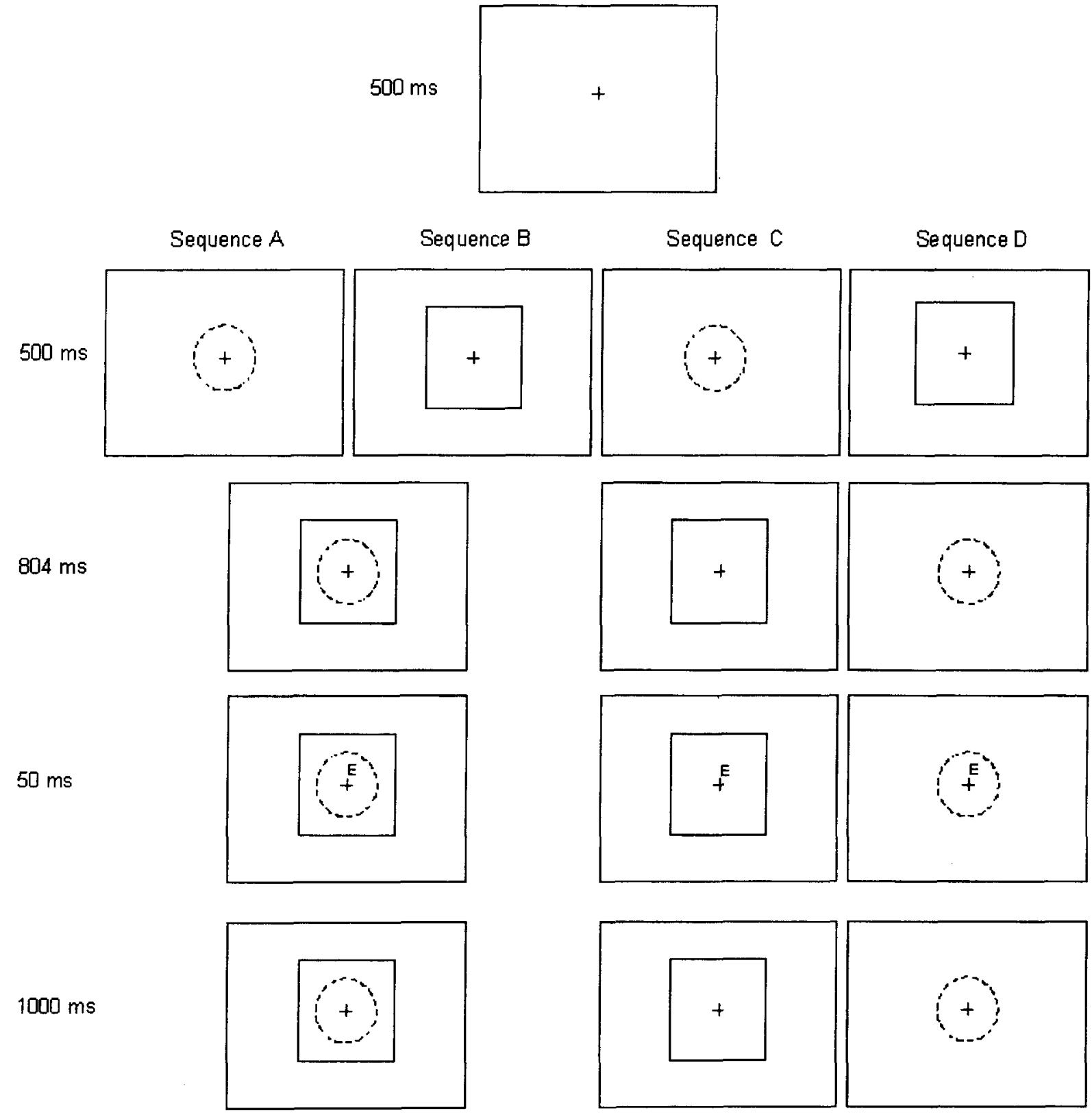

Figure 2. Schematic representation of the sequence of events in Experiment 2. Solid outlines were red; dotted outlines were green.

reproducing the cue size effect. In accordance with this prediction, RTs were faster for Sequence D than for Sequence $C$.

The results were clear, showing that the subjects were able to voluntarily narrow the size of the attentional focus toward stimulus position (around the fixation point) only when an object delimiting that area (i.e., the small cue) was present. By contrast, when only the large cue was present, the subjects were unable to narrow the size of the focus. These results are consistent with those reported by Castiello and Umiltà (1992, Experiment 3), who showed that subjects were unable to manipulate the focus size in the absence of an object on which to anchor attention.

On the basis of Experiment 2, we can provide an answer for why subjects failed to restrict the focus of attention to stimulus position in Experiment 1. Although they knew in advance the stimulus position, when the large cue was presented alone the subjects could not ignore it and narrow the focus toward its center. It is likely that this was because it is not possible to adjust the size of the focus to an empty spatial location, which the center of an object presumably is. ${ }^{2}$ In contrast, when both cues 


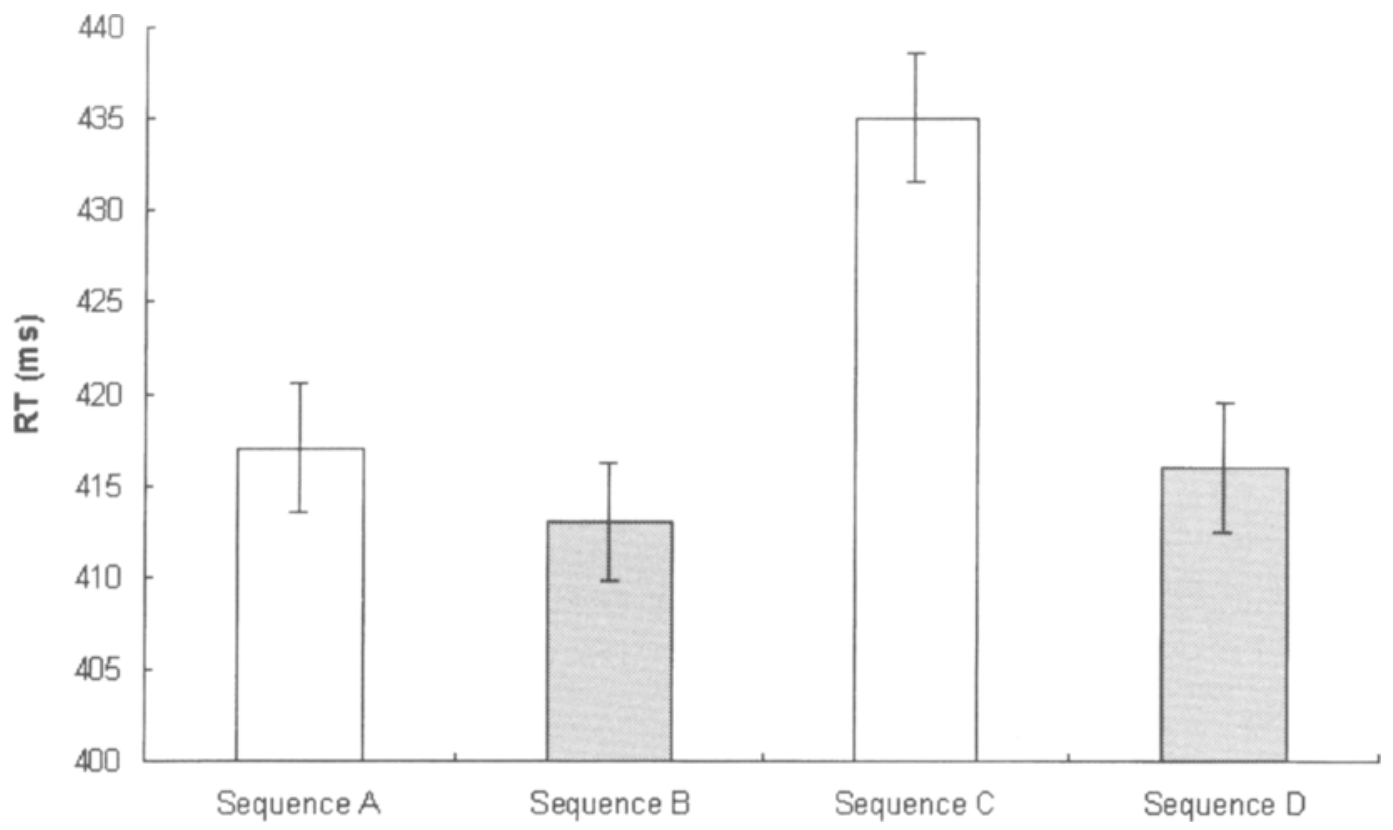

Figure 3. The first cue (present or absent) $\times$ second-cue size (small or large) interaction (Experiment 2). Sequence $A$ represents the second cue large and first cue present condition; Sequence $B$ represents the second cue small and first cue present condition; Sequence $C$ represents the second cue large and first cue absent condition; and Sequence $D$ represents the second cue small and first cue absent condition. Bars represent standard errors.

were present and when enough time (804-msec SOA) was given to manipulate the focus, the subjects narrowed the focus to the smaller cue. In light of the present results, for focusing, the term voluntary should perhaps be replaced by the term weakly voluntary, in that the actual size of the focus does not seem to be completely under endogenous control.

In conclusion, the findings of Experiment 2 can be summarized as follows: (1) The cue size effect can be obtained with a target discrimination task (Eriksen \& St. James, 1986) and in the absence of eye movements, and (2) the degree of endogenous control over the size of the focus is limited.

\section{EXPERIMENT 3}

The results of Experiments 1 and 2 provided evidence about the top-down voluntary component of focusing. This is because, at an 804-msec SOA, an automatic process is very unlikely to play any role in visual attention (for orienting, see Müller \& Findlay, 1988; Müller \& Rabbitt, 1989). Hence, the cue size effect observed at such an SOA would be due to the voluntary top-down component only. With the present and the next experiment, we investigated the automatic bottom-up component of focusing.

There is much evidence that, for orienting, the abrupt onset of a stimulus automatically captures attention (e.g.,
Folk et al., 1992, 1994; Müller \& Rabbitt, 1989; Theeuwes, 1994; Warner et al., 1990; Yantis \& Hillstrom, 1994; Yantis \& Jonides, 1990). Similarly, it is conceivable that, once orienting has taken place, another process comes into play - that is, the automatic focusing on the object. The idea is that a sort of focusing reflex exists, consisting in the automatic adjusting of the attentional focus to the size of the observed object. In particular, we suggest that initially (about $100 \mathrm{msec}$ ), focusing depends on an automatic mechanism, triggered by the abrupt onset of a new element in the visual field. Such a focusing reflex would have a biologic plausibility, because it would provide the central system with the possibility of identifying the new object's features.

As was mentioned above, Maringelli and Umiltà (1998) made a first attempt to study focusing in isolation from orienting, exploiting the cue size effect observed at a 100msec SOA as an index of the automatic component of focusing. However, in the procedure they used, exogenous and endogenous mechanisms may have been confounded, because one cannot rule out top-down modulation even with an SOA as brief as $100 \mathrm{msec}$. Thus, although we agree with the notion that focusing can be triggered in a bottom-up fashion, we also believe that those results provided only indirect evidence about this phenomenon.

Therefore, the main purpose of this experiment was to provide more direct evidence for bottom-up focusing. For the orienting of attention, the two components- 
exogenous, or automatic, and endogenous, or controlledhave been extensively investigated (e.g., Jonides, 1981; Müller \& Findlay, 1988; Müller \& Rabbitt, 1989; Posner, 1980; Riggio \& Kirsner, 1997). In particular, many studies have been devoted to addressing the features of the automatic component (e.g., Henderson \& Macquistan, 1993; Jonides, 1981; Jonides, Naveh-Benjamin, \& Palmer, 1985; Jonides \& Yantis, 1988; Warner et al., 1990; Yantis \& Jonides, 1990).

To evaluate the automaticity of an abrupt visual onset in capturing attention, two criteria were used, load insensitivity and intentionality (Yantis \& Jonides, 1990). Whereas there is general agreement that automatic orienting is not affected by a secondary memory task or by the level of validity of the cue (Jonides, 1981), the evidence is less clear for the criterion of intentionality. Some studies (Koshino, Warner, \& Juola, 1992; Warner et al., 1990; Yantis \& Jonides, 1990) have clearly shown that the strength of capture by an abrupt-onset stimulus can be modified by prior focusing elsewhere. As Yantis and Jonides (1990) stated: "The overall conclusion to which we are led is that attentional capture by abrupt stimulus onset is not strongly automatic because, although it satisfies the load-insensitivity criterion, it does not strictly satisfy the intentionality criterion" (p. 133).

Consequently, because the intentionality criterion seems to be critical for automaticity, we decided to test it. The experimental situation investigated whether the subject, while voluntarily focusing, can prevent automatic focusing on a different object that suddenly appears around or inside the object observed.

\section{Method}

Subjects. Twenty students from the University of Padua ( 8 males and 12 females), all right-handed and with normal vision, participated. They were not aware of the goal of the experiment and had not taken part in the previous experiments.

Apparatus and Procedure. The apparatus and procedure were the same as those in Experiment 1--that is, there was only the 804msec SOA, but on half of the trials, $66 \mathrm{msec}$ before stimulus onset, another cue, different in shape, suddenly appeared inside or outside the previous cue (see Figure 4).

The subjects were clearly instructed to focus attention on the circle cue, ignoring any other object. The trials were presented randomly; thus, the subject did not know in advance in which kind of trial he/she was performing.

The total number of trials was 152 , divided into two blocks of 76 trials. The trials of each block were distributed as follows: 30 trials with the circle cue only ( 15 with the small cue and 15 with the large cue) and 30 with both the circle and the square (15 with the small cue and 15 with the large cue). The square cue acted as a distractor. There were 16 catch trials (about $12 \%$ of the total trials).

\section{Results}

Errors (i.e., responses on catch trials) were fewer than $3 \%$ and were not analyzed. An ANOVA for repeated measures, in which the factors were cue size $\left(2.5^{\circ}\right.$ or $\left.7.5^{\circ}\right)$ and distractor (present or absent), was conducted on RTs. Neither the main effect of cue size $[F(1,19)=0.470, p=$ $.830]$, nor the main effect of distractor $[F(1,19)=0.225$, $p=.641]$ was significant. Instead, the cue size $\times$ distrac- tor interaction was significant $[F(1,19)=26.890, p<$ $.001\left(2.5^{\circ}\right.$ cue, $M=329 \mathrm{msec}, S D=47 ; 2.5^{\circ}$ cue $+7.5^{\circ}$ square, $M=345 \mathrm{msec}, S D=55 ; 7.5^{\circ}$ cue, $M=347 \mathrm{msec}$, $S D=42 ; 7.5^{\circ}$ cue $+2.5^{\circ}$ square, $M=325 \mathrm{msec}, S D=49$ ); see also Figure 5]. In the absence of the distractor, there was a clear cue size effect of $18 \mathrm{msec}$. In contrast, the distractor reversed the cue size effect $(-20 \mathrm{msec})$.

\section{Discussion}

The present experiment was designed to investigate whether subjects were able to prevent automatic focusing caused by a new object. Because, for orienting, the most critical automaticity criterion is intentionality (Warner et al., 1990; Yantis \& Jonides, 1990), we used intentionality to test automatic focusing.

While subjects were voluntary focusing on the cue (a circle), on some trials a distractor (a square) appeared around or inside the cue. We expected that, if the abrupt onset of a new object disrupted voluntary focusing, the pattern of RTs should be as follows. When no distractor was presented, there should be a cue size effect caused by the top-down component. When the distractor was presented, the cue size effect should be reversed because of the bottom-up component-namely, the RT for the small circle should be slower than that for the large circle. In fact, when attention is voluntarily focused on the small circle and a big distractor square suddenly appears around it, the RT should increase, because the focus would automatically be enlarged to fit the size of the distractor. Conversely, the RT should decrease if attention is focused on a large circle and a small square appears inside it.

The results of Experiment 3 supported this prediction (see Figure 5), thus providing evidence in favor of an automatic, stimulus-driven component involved in attentional focusing. They were very similar to those obtained by Theeuwes (1991, Experiment 1), who showed that, at the 600-msec SOA, focused attention was disrupted by a nearby abrupt onset, whereas a peripheral onset did not affect performance (see also Yantis \& Jonides, 1990). He interpreted these findings as representing a need to resize the attentional spotlight, suggesting that "the extent to which abrupt onsets interfere depends on the size of the spotlight. Within the spotlight of attention, abrupt onsets do interfere." (Theeuwes, 1991, p. 87).

The present experiment extends Theeuwes' (1991) findings, in that it clearly shows that voluntary focusing is disrupted not only by an abrupt onset that occurs inside the focus of attention (i.e., the small cue displayed inside the large cue), but also by an abrupt onset presented around the focus of attention (i.e., the large cue displayed around the small cue). In particular, it should be noted that voluntary focusing on the small $100 \%$-valid cue was disrupted by the abrupt onset of the large cue outside the spotlight of attention. It is clear that an object displayed outside the focus can summon attention.

How can this result be reconciled with those of previous studies (e.g., Theeuwes, 1991; Warner et al., 1990; Yantis \& Jonides, 1990) showing that abrupt onsets do not 


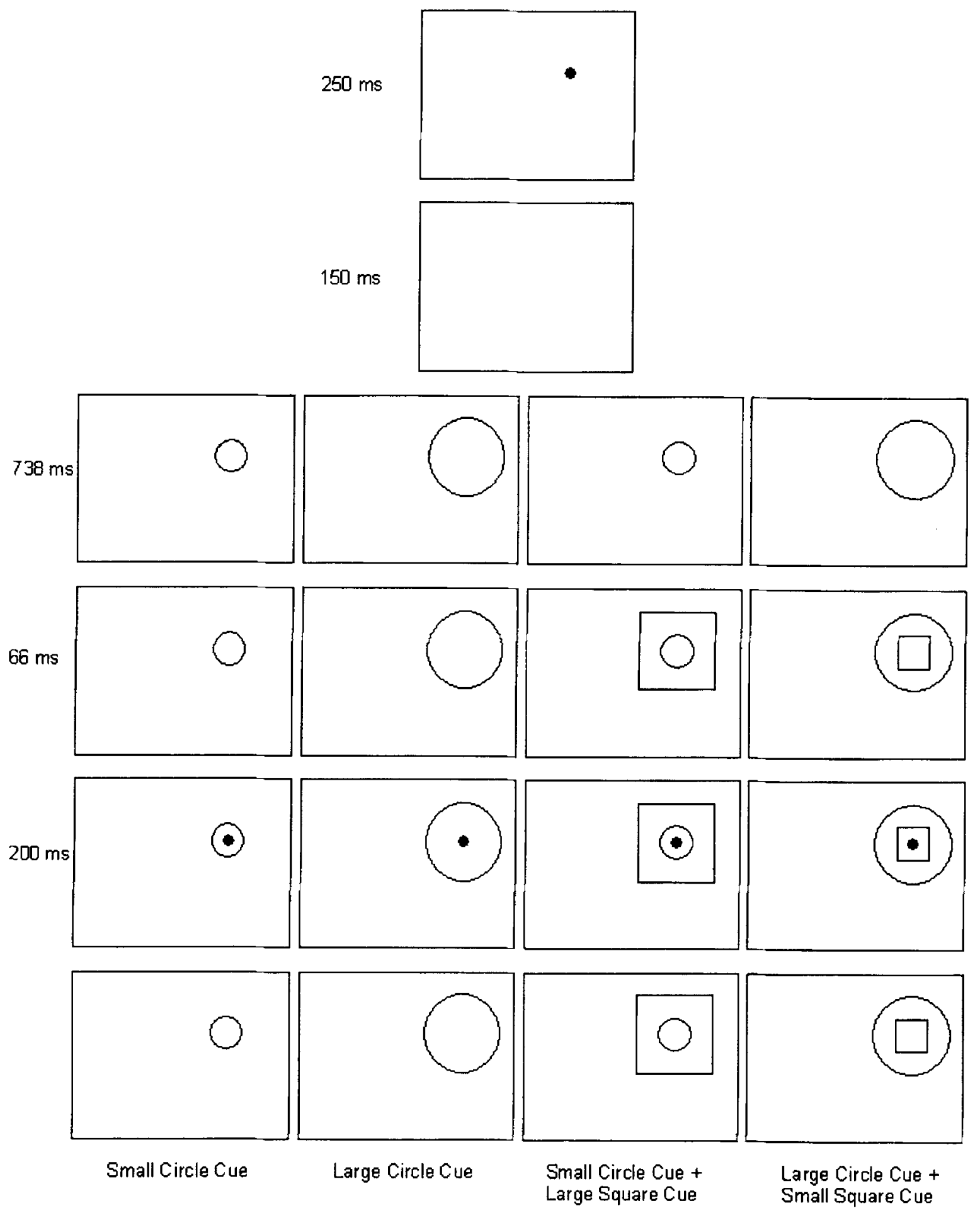

Figure 4. Schematic representation of the sequence of events in Experiment 3.

capture attention when the visual system is in a focused attention mode? As was pointed out in the introduction, we suggest that the critical point is that our study investigated the focusing process in isolation, in the absence of orienting, which, in contrast, was involved in those previous studies. It is likely that if attention is fully focused on a location, abrupt onsets in another part of the visual field are unable to summon the spotlight of attention, because orienting of attention can be prevented by the focused attention mode. By contrast, if an object suddenly appears inside or just outside the object on which attention is focused, no attention and/or eye movements are 


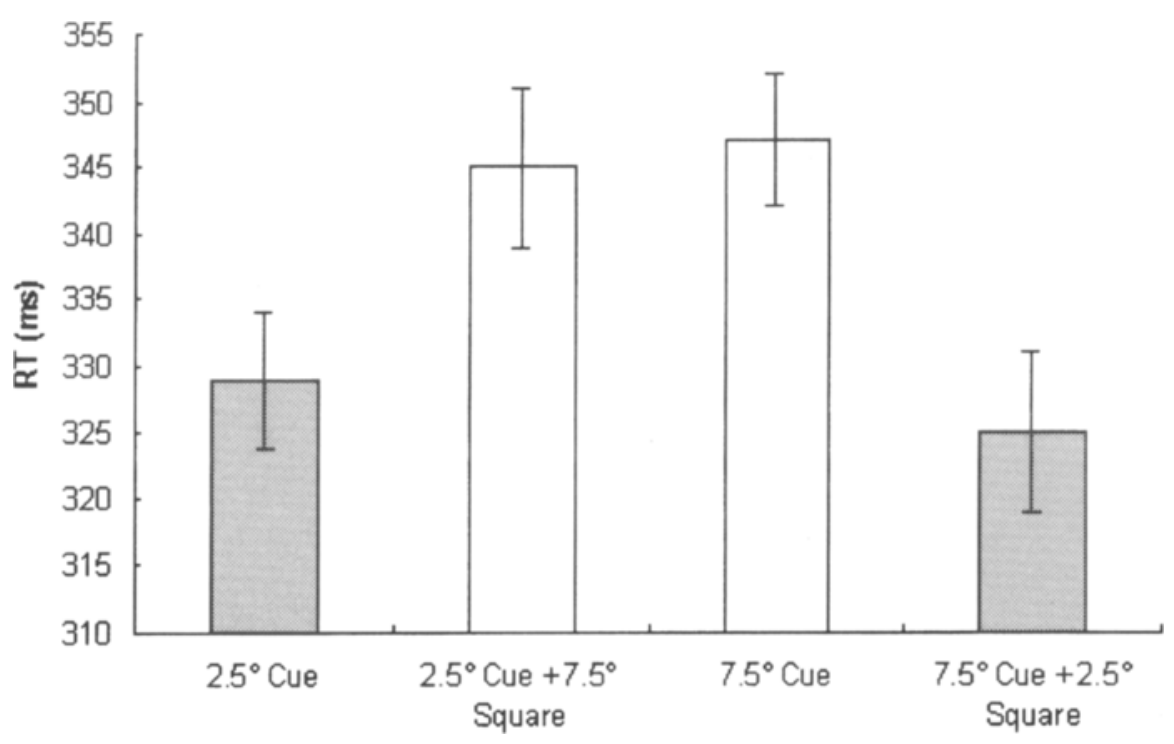

Figure 5. The cue size $\times$ distractor (present or absent) interaction (Experiment 3). Bars represent standard errors.

needed, but rather, the focus is readjusted to the size of the new object. This is further evidence supporting the notion that focusing is different from orienting. We will, however, consider a different interpretation in the General Discussion section. Also, it is interesting to note that automatic focusing seems to meet the intentionality criterion, which, however, is not completely satisfied in the case of automatic orienting (Theeuwes, 1991; Warner et al., 1990; Yantis \& Jonides, 1990).

The present results are also critical to ruling out a further nonattentional account of the cue size effect. In fact, although the target appeared always in the center of the cue, thus in part eliminating positional uncertainty, it should be more difficult to estimate the center of a large cue than that of a small cue. It follows that the attended area is more variable in the large-cue condition, producing slower RTs. However, the slower RTs observed in the large-distractor-cue condition were obtained when the small cue was also present (see Figure 4). In comparison with the small-cue condition, RTs lengthened in the distractor condition, despite the fact that position uncertainty did not vary across the two conditions, because the small cue was present in either case. This strongly suggests that the cue size effect is a true attentional effect and renders the spatial uncertainty interpretation much less convincing.

\section{EXPERIMENT 4}

For the voluntary focusing of attention, we have already provided evidence that the cue size effect can be observed with both a simple RT task (Experiment 1) and a choice RT task (Experiment 2). Hence, because in Ex- periment 3 , we addressed the automatic component of focusing by using a simple detection task, the aim of the present experiment was to investigate the same mechanism also by means of a target discrimination task. The subjects were required to pay attention to a given figure only (the small green circle), within which the target was displayed after about $800 \mathrm{msec}$, and to ignore the surrounding object (the large red square), if present. As in Experiment 3, our prediction was that the sudden occurrence of a large red square around the attended figure just $100 \mathrm{msec}$ before target onset would cause the focus to automatically readjust to the new object size. As a consequence, RTs for discriminating the target, appearing inside the small green circle, should increase.

In addition, with regard to orienting, previous studies have shown that onset is not unique as a transient signal that grabs attention in an automatic fashion, in that offset seems to be able to elicit an automatic attentional capture too (Miller, 1989; Theeuwes, 1991). Theeuwes (1991), in particular, demonstrated that, under conditions of unfocused attention, visual offsets seem to be as effective as visual onsets in summoning spatial attention. Therefore, a second goal of the present experiment was to investigate whether focusing can also be triggered by the transient signal produced by the offset of an object. Specifically, for what concerns the offset condition, we examined whether a subject can prevent automatic focusing caused by the disappearance of an object located around the attended figure.

\section{Method}

Subjects. Thirteen students at the University of Padua ( 5 males and 8 females), all right-handed and with normal or corrected-to- 
normal vision, served as subjects. They were not aware of the purpose of the experiment and had not taken part in the previous experiments.

Apparatus and Procedure. The apparatus was the same as that in Experiment 2. At the beginning of the trial, a fixation point $\left(0.1^{\circ}\right)$ was presented at the center of the screen and remained on until the end of the trial. Then, four different cue-target sequences were presented to every subject (see Figure 6).

Sequence A. After $500 \mathrm{msec}$ from onset of the fixation point, the small cue was presented for $804 \mathrm{msec}$. At the end of the SOA, the target was briefly flashed for $50 \mathrm{msec}$ around the fixation point.

Sequence B. After $500 \mathrm{msec}$ from onset of the fixation point, the small cue was presented for $704 \mathrm{msec}$; then, the large red square was presented around the green circle for $100 \mathrm{msec}$ before stimulus onset. At the end of the SOA, the target was briefly flashed for $50 \mathrm{msec}$ around the fixation point.

Sequence C. After $500 \mathrm{msec}$ from onset of the fixation point, the small cue and the large square were presented together for $804 \mathrm{msec}$. After the end of the SOA, the target was briefly flashed for $50 \mathrm{msec}$ around the fixation point.

Sequence D. After $500 \mathrm{msec}$ from onset of the fixation point, the small cue and the large square were presented together for $704 \mathrm{msec}$; then, $100 \mathrm{msec}$ before stimulus onset, the square disappeared around the green circle. At the end of the SOA, the target was briefly flashed for $50 \mathrm{msec}$ around the fixation point.

At stimulus onset, the subjects had to press the appropriate response key (the Q key for the letter $\mathrm{H}$ and the $\mathrm{P}$ key for the letter $\mathrm{E}$ ) on the keyboard as quickly as possible, and the RT was recorded. The maximum time allowed for the response was $1 \mathrm{sec}$.

Each subject performed all four of the sequences, which were randomly presented within a block of trials. The total number of trials was 80 , divided into two blocks of 40 . The trials of each block were equally distributed among the four sequences. Before the experiment began, the subjects performed some training trials until they felt confident with the task. As in Experiment 2, the subjects were also instructed to keep the eyes at fixation at any time during the trial. In addition, eye movements were monitored on line by means of an infrared ray device throughout the trial. Those trials in which an eye movement was detected were discarded but not replaced.

\section{Results}

Errors, including eye movements, were fewer than $4 \%$ and were not analyzed. Data were entered into an ANOVA for repeated measures, in which the only factor was type of sequence (A, B, C, or D), which showed significant results $[F(3,36)=6.109, p<.005]$. The subjects showed the same mean RTs in three out of four conditions (Sequence A, $M=436 \mathrm{msec}, S D=40$; Sequence C, $M=$ $436 \mathrm{msec}, S D=41$; Sequence D, $M=436 \mathrm{msec}, S D=$ 37 ), whereas Sequence $B$ was the only condition that significantly differed from the others $(M=456 \mathrm{msec} ; S D=$ 44; see Figure 7).

\section{Discussion}

Basically, the results of Experiment 4 confirmed those from Experiment 3, showing that, when a new task-irrelevant object suddenly occurred around the attended cue, the focus of attention was automatically readjusted to its size. In comparison with Sequence A, when only the small green circle cue was presented, Sequence B produced slower RTs (mean difference, $20 \mathrm{msec}$ ), likely because the onset of the large red square $(100 \mathrm{msec}$ before target display) caused the focus size to change. So, even though the subjects knew in advance that the target ap- peared only inside the small circle, when the target occurred the focus of attention was still fitted to the wider area covered by the large red square. It is likely that the short interval $(100 \mathrm{msec})$ between presentation of the large square and appearance of the target was not enough for the subject to voluntarily narrow the focus to the small circle cue. By contrast, as was already shown in Experiment 2, when the large square and the small circle cue were presented together (Sequence C), an 804-msec SOA was sufficient to restrict the focus toward the area covered by the circle. Then, the mean RTs for Sequence C $(436 \mathrm{msec})$ did not differ from those for Sequence $A$ (436 msec).

Given that for orienting there is evidence that offset is able to summon attention (e.g., Miller, 1989; Theeuwes, 1991), with this study we sought to establish whether automatic focusing could also be triggered by the transient signal generated by the offset of an object around the attended figure. If the offset of the large square around the small attended cue is able to elicit a new bottom-up focusing process, we should expect slower RTs in Sequence D than in Sequence A. However, this was not the case, in that RTs were exactly the same in both conditions. Therefore, it seems that, whereas the sudden occurrence of a new object is able to produce an automatic focusing reflex, the disappearance of the same object is not. This result suggests that, at least for focusing, the transient signals generated by an onset and by an offset do not have the same strength in summoning attention and, specifically, in changing the focus size. A simpler explanation might be that offset provides a weaker transient signal than onset does and that this weaker signal is not able to overcome the top-down modulation involved in voluntary focusing. However, a more interesting account of the present findings invokes the object-based theory of attention (e.g., Duncan, 1984; Kanwisher \& Driver, 1992). This position holds that attention is not attracted by luminance increments associated with the occurrence of a new object in the visual field (e.g., Breitmeyer \& Ganz, 1976), but by the object per se. In accord with that, the present experiment supports the notion that a simple luminance change alone is not sufficient to capture attentional focusing but that a change in the width of the focus is automatically triggered when the transient signal is produced by the appearance of a new object.

Finally, the findings of the present experiment replicated those of Experiment 2, showing that the cue size effect can be obtained, in the absence of eye movements, by using a target discrimination task.

\section{GENERAL DISCUSSION}

The main purpose of the present study was to provide evidence that focusing is a separate process from orienting and to explore both its exogenous, or automatic, and endogenous, or voluntary, components. Findings from early studies had suggested the distinction between focusing and orienting (Castiello \& Umiltà, 1990; Stoffer, 

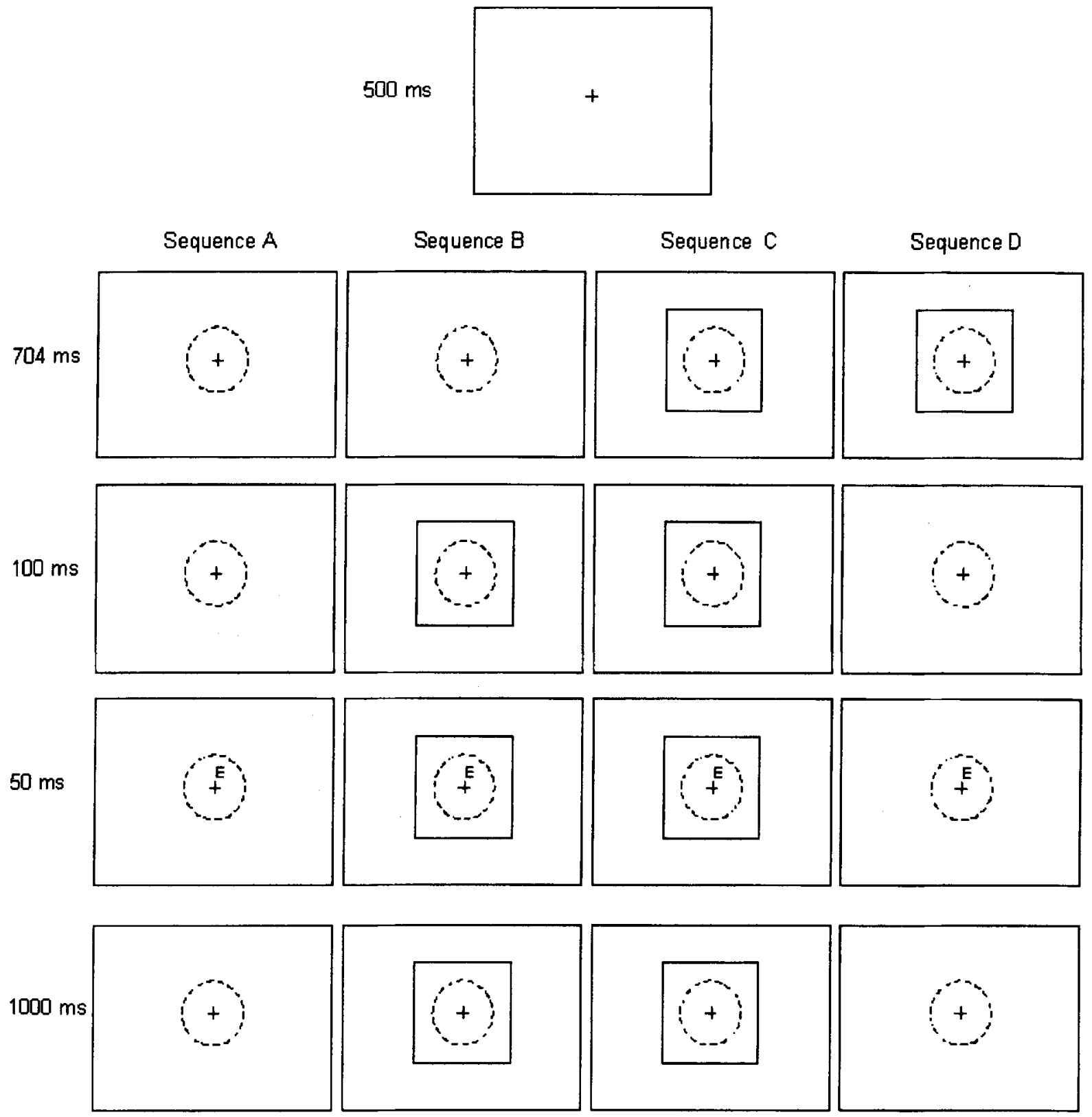

Figure 6. Schematic representation of the sequence of events in Experiment 4. Solid outlines were red; dotted outlines were green.

1991). Recently, the studies of Benso et al. (1998) and Maringelli and Umiltà (1998) provided some support to the notion that shifting attention and focusing attention are distinct processes. However, these previous studies provided only indirect evidence with regard to this issue. Hence, we carried out four experiments in order to study focusing in isolation in a clearer and more direct manner. In addition, because the studies devoted to orienting distinguished two different ways to produce a movement of attention in the visual field, one automatic and the other voluntary, we tried to show that this distinction also holds for focusing. As has already been suggested by Benso et al., we propose that, after orienting is completed, another process is activated, by which the attentional focus is adjusted to the object size. Like orienting, focusing would be governed by two separate mechanisms, an early stimulus-driven component triggered by the abrupt onset of the object and a second goal-directed component by means of which the size of the focus is voluntarily maintained.

We started by exploring the voluntary mechanism of focusing. In Experiment 1, subjects were submitted to a 


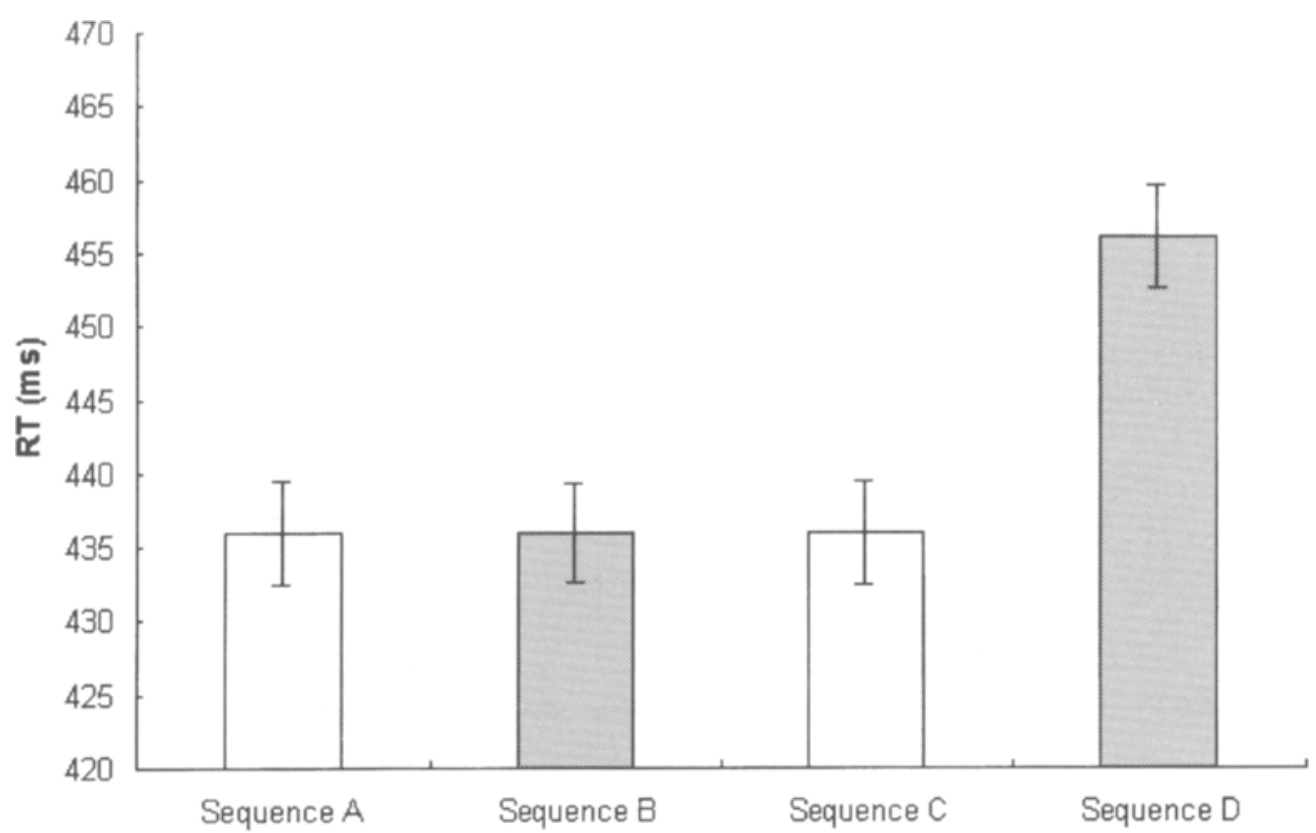

Figure 7. Main effect of type of sequence (Experiment 4). Sequence A represents the condition in which only the small circle cue was presented; Sequence B represents the condition in which the small circle cue was followed by the large square cue; Sequence $C$ represents the condition in which the small circle and the large square cue were presented together; and Sequence $D$ represents the condition in which first the small circle and large square cues were presented together and then the large cue was turned off. Bars represent standard errors.

simple RT task, consisting in the detection of a small dot presented inside a circle cue of two different sizes after an $804-\mathrm{msec}$ SOA. The results showed that the cue size effect- that is, the RTs for target detection were slower for the large cue than for the small cue. In our view, the cue size effect was obtained because RTs become faster as attentional resources become more concentrated in a narrower area. However, considering that the stimulus occurred always at the center of the cue after $804 \mathrm{msec}$, one may wonder why the subjects did not use this information to voluntary narrow the focus exactly on the location of the target. Experiment 2 answered this question by demonstrating that the width of the focus depends on the size of the attended figure and that it cannot be changed unless another perceptual object, the size of which the focus fits, is present. Basically, it seems that it is not possible to focus on an empty spatial location, which the center of an object is (see also Castiello \& Umiltà, 1992). Of course, this finding undermines the idea of a completely endogenous focusing mechanism and, rather, suggests a weakly voluntary control. It is likely that this was the reason why, in Experiment 1, the subjects were unable to narrow the width of the attentional focus to the center of the cue and, instead, produced the cue size effect. Therefore, taken together, the results of Experiments 1 and 2 supported the notion of an at least partially voluntary mechanism for focusing. If the experimental conditions are such as to permit it, the subject can exert a top-down con- trol, choosing the figure-delimited area over which to produce active focusing.

Experiments 3 and 4 investigated automatic focusing. The hypothesis was that when a new object appears in the visual field, the focus of attention is automatically adjusted to its size. This is consistent with object-based theories of visual attention that maintain that attention is allocated to the objects present in the visual field (e.g., Duncan, 1984; Kahneman \& Treisman, 1984; Kahneman et al., 1992; Kanwisher \& Driver, 1992; Yantis \& Hillstrom, 1994). Although the studies regarding attentional capture were primarily concerned with the spatial movement of the focus, it is possible that the process of focusing also is controlled by a similar automatic mechanism. We termed this process the focusing reflex and proposed that it works in a bottom-up fashion.

Given that, for what concerns orienting, the most critical criterion for automaticity is intentionality (Warner et al., 1990; Yantis \& Jonides, 1990), in Experiment 3 we used this criterion to test automatic focusing. The results showed that subjects, while voluntary focusing on an object, cannot avoid automatically focusing on another object that suddenly appears around or inside the attended figure (see also Theeuwes, 1991, Experiment 1). This satisfies the criterion of intentionality.

In addition, the results of Experiment 3 are relevant to another issue. Considering that the whole set of experiments presented here is based on the notion that the cue 
size effect indexes control of the attentional focus, it is important to point out that Experiment 3 allows us to rule out an alternative explanation for the cue size effect. From our point of view, the cue size effect is obtained because RTs becomes faster as attentional resources become more concentrated. However, one may argue that, in comparison with a large cue, a smaller cue produces faster RTs merely because positional uncertainty is reduced and/or it is perceptually easier to find the center of a small circle than that of a large circle. This would be the spatial hypothesis, as opposed to the attentional hypothesis. Several aspects of the results are at odds with the spatial hypothesis. First, because target position was fixed at the center of the cue, positional uncertainty was minimal. Second, and more crucial, in the distractor condition of Experiment 3 , the cue size effect was obtained even though the small cue was always present when the stimulus was shown (see Figure 4) and, therefore, there was no positional uncertainty. Thus, it can be assumed that the cue size effect represents a true attentional effect.

The plausibility of a stimulus-driven mechanism for focusing was also supported by Experiment 4 . The sudden occurrence of a large object around the small 100\%valid cue just prior to target onset produced the automatic enlargement of the focus width, which was adjusted to the new object's size, thus slowing RTs for target discrimination. Also, the results showed that the focusing reflex was triggered only by the transient signal associated with the onset of a new object, whereas this did not happen when the transient signal was provided by the offset of the same object. By contrast, studies from orienting demonstrated that, when attention is not fully focused on a given spatial position, visual offset, as well as onset, is able to grab the spotlight of attention. Therefore, the fact that visual onset and offset seem to affect orienting and focusing in a different manner is further evidence that the two processes may rely on different mechanisms. However, we do not propose that focusing and orienting are completely independent processes, in the sense that one can take place in the absence of the other. Indeed, although the present experiments showed that focusing can take place when orienting is excluded, it is very likely that when orienting is triggered, the two processes are simultaneously active and, possibly, linked. As was suggested by Vincent Brown (personal communication, May 17, 1998), an analogy for orienting and focusing could be reaching and grasping: While the hand moves in the direction of the object to be grasped, it is simultaneously adjusting its shape to fit the object.

Alternatively, it could be that focusing is not an independent process from orienting but, rather, just a part of it. Specifically, the focusing of attention might be thought of as being the engage mechanism proposed by Posner and his colleagues (e.g., Posner et al., 1987), which would make focusing a component of orienting. When attention has moved toward an element in the visual field, the last part of the shifting process would consist in focusing or engaging the focus to the object size. Particularly interesting would be a study investigating the focusing process in those patients who suffer from pulvinar lesions. As Posner and Petersen (1990; see also Petersen, Robinson, \& Morris, 1987; Posner, 1988) have argued, although these patients do not show any problems in disengaging or moving attention, they have a specific deficit in the engaging mechanism. The idea would be to submit these patients to a focusing task, to determine whether or not they exhibit the cue size effect. If our hypothesis that focusing is different from orienting and, more specifically, from engaging is correct, we should expect these patients to produce the cue size effect.

As was already pointed out, our standpoint is that the abrupt onset of an object produces both the orienting of attention toward its position and the adjusting of the attentional focus to the object size. With regard to focusing, evidence suggests that initially it is triggered in a stimulusdriven fashion by the occurrence of a new element. The focusing reflex seems to be a fairly strong mechanism, because subjects were not able to overcome it while they were voluntarily focusing on a to-be-attended figure. So, at least in the experimental conditions prevalent in the present study, the focusing reflex satisfied the strongest criterion for automaticity-namely, intentionality.

However, a caveat on the automatic focusing component should be considered. By definition, an automatic, or stimulus-driven, attentional capture occurs when attention is summoned independently of the goals and intentions of the observer. For orienting, early studies showed that an irrelevant spatial cue, briefly presented before imperative stimulus onset, was able to disrupt performance, lengthening RTs for target detection when it appeared in a different location from the target (e.g., Posner \& Cohen, 1984). That was taken as evidence that attention can be automatically allocated in the visual field despite the intention of the observer. Yet, the contingent capture hypothesis proposed by Folk et al. (1992) undermines these findings, challenging the notion that a real stimulus-driven attention capture exists. In this perspective, an involuntary shift of attention to a given stimulus depends on whether the stimulus shares feature(s) that is (are) critical to perform the task (Folk et al., 1992; Folk et al., 1994). Previous studies that explored automatic attentional capture failed to notice that the visual features that defined the cue also defined the target. Therefore, because subjects were set to respond to an onset target, the capture observed by the onset cue cannot be considered entirely automatic, in that top-down attentional control was involved.

Similar considerations apply to the conditions under which we observed the automatic focusing of attention. The fact that the subjects were set to respond to an onset target no doubt provided the conditions for contingent capture and guaranteed that an onset cue would grab attention. However, even though the capture of focal attention we observed might have been modulated by the attentional set adopted, this does not exclude the possibility that, as was demonstrated by Experiments 3 and 4, the fo- 
cusing mechanism is involuntarily triggered in response to the onset of a new object. In contrast, as has been noted in previous research (Koshino et al., 1992; Yantis \& Jonides, 1990), the orienting mechanism does not automatically respond to the appearance of a new object if attention is already fully focused elsewhere.

It is worth noting, however, that in Yantis and Jonides (1990; see also Koshino et al., 1992; Warner et al., 1990), subjects were required to focus attention on a position in the hemifield opposite from the abrupt onset of the new object, whereas in our study, attention was centered at the location of new object. Thus, in the Yantis and Jonides (1990) study, the new object was far from the focus of attention, whereas in our study, the new object appeared much closer to the focus of attention. Assuming that in the present study, as well as in that by Yantis and Jonides (1990), what mattered was a shift of attention, the different distances between the new object and the focus of attention might explain why Yantis and Jonides (1990) showed that an abrupt onset did not capture attention, whereas we found that the abrupt appearance of the large cue (i.e., the new object) captured attention (as reflected in elevated RT) when it was focused on the small cue.

We have used the inverse relation between cue size and RTs as an index of the focusing process. However, an alternative interpretation might account for this inverse relation. Work on object-based attention suggests that a filtering cost is incurred when two distinct perceptual objects compete for attention (e.g., Kahneman, Treisman, \& Burkell, 1983; Treisman, Kahneman, \& Burkell, 1983). Basically, these studies demonstrated that the presence of an irrelevant distractor delays RTs to the target item, even when the distractor does not compete with the target for response. One may argue that, in our paradigm, the subjects focused only on the target (i.e., the dot or the letter) and the cue was treated as a to-be-ignored distractor. If we assume that the greater the size of the distractor, the more were the resources required to filter it, it follows that the cue size effect would represent a simple filtering cost. However, such a filtering cost interpretation cannot accommodate some of the present results. First, Experiment 4 showed that RTs in the small-cue condition were as fast as those in the small-plus-large-cue condition. The filtering cost hypothesis would predict a different result, because filtering two objects should require more attentional resources, leading to slower RTs. However, one may maintain that the two objects were integrated into a single one, so that they were seen as belonging together (Treisman et al., 1983). This might explain similar RTs in the two conditions. The second, and more serious, problem faced by the filtering cost hypothesis originates from the results of Experiment 3 . The crucial observation here is that the sudden occurrence of a small cue inside the large cue just $100 \mathrm{msec}$ before target presentation speeded RTs, which became as fast as in the single-small-cue condition. Again, the filtering cost hypothesis cannot ex- plain why the appearance of another object led to a better performance than in the single-large-cue condition, which also rules out explanations based on the perceptual integration of two cues into a single one. By contrast, as was discussed earlier, the results of Experiments 3 and 4 are consistent with the focusing hypothesis. Also, Kahneman et al. (1983) found that the sudden disappearance of an object produced almost the same cost as the appearance of a new object. They concluded that the cost of filtering would be due to the processing of competing events, rather than to the competition between objects per se. The results of Experiment 4 were inconsistent with this interpretation, because the sudden offset of the large distractor did not increase RTs. It should be noted that, whereas in the present study orienting was not involved, in Kahneman et al.'s (1983) study stimuli were presented peripherally and, therefore, orienting was presumably involved. As Miller (1989) has demonstrated, offset is able to elicit a spatial shift of attention, and this might explain why, in Kahneman et al.'s (1983) study, the sudden disappearance of an element delayed RTs to the target.

Finally, one might try to interpret the present results with reference to another version of object-based attention: Perhaps, the cost incurred when switching attention between cues is an instance of the so-called two-object cost (see, e.g., Duncan, 1984; Kanwisher \& Driver, 1992). Note that in Experiments 3 and 4, the subjects were set to attend to an object and, thus, the experimental conditions were such as to produce an object-based attentional capture, as is suggested by the contingent capture hypothesis (Folk et al., 1992; Folk et al., 1994). Therefore, the lengthening of RT owing to the abrupt onset of the large cue would be explained by assuming that attention switches from one object to the other. However, this interpretation cannot account for the shortening of RT observed when subjects are attending to a large cue and, suddenly, a small cue is presented.

In conclusion, many aspects of the present results support the notion that the process of focusing is different from orienting. First, as for orienting, the empirical evidence about the automatic shift of attention led Yantis (1993) to state that "5) when the observer focuses attention on a spatial location in advance, then an onset singleton elsewhere does not capture attention (Theeuwes, 1991; Yantis \& Jonides, 1990); 6) . . . if attention is focused on a spatial location in advance, then no singleton of any kind will capture attention" (p. 680). By contrast, the results of Experiments 3 and 4 clearly showed that when attention was focused on the cue, the sudden occurrence of a distractor in close proximity automatically changed its size (see also Theeuwes, 1991), so that the focus was automatically adjusted to the new object size. It should be noted that this occurred despite the fact that subjects were explicitly asked not to pay attention to any element other than the circle cue. Second, it seems to be equally likely that the shift of spatial attention will be elicited by either an onset or an offset transient signal, whereas focusing is 
triggered only by a sudden onset. These differences between focusing and orienting lead us to suggest that focusing is different from orienting.

The present study also provided evidence that focusing is not governed by a unique mechanism. Two processes appear to govern it: an early, short-lasting process that adjusts the focus of attention to the object size as soon as it appears and a later, longer lasting voluntary process that is responsible for maintaining attention in the focused mode.

\section{REFERENCES}

Benso, F., Turatto, M., Mascetti, G. G., \& Umiltà, C. (1998). The time course of attentional focusing. European Journal of Cognitive Psychology, 10, 373-388.

BREITMEYER, B. G., \& GANZ, L. (1976). Implications of sustained and transient channels for theories of visual pattern masking, saccadic suppression, and information processing. Psychological Review, 83, $1-36$.

Castiello, U., \& Umiltà, C. (1990). Size of the attentional focus and efficiency of processing. Acta Psychologica, 73, 195-209.

CAstiello, U., \& Umiltà, C. (1992). Splitting focal attention. Journal of Experimental Psychology: Human Perception \& Performance, 3, 837-848.

DUNCAN, J. (1984). Selective attention and the organization of visual information. Journal of Experimental Psychology: General, 113, 501517.

EgeTH, H. (1977). Attention and preattention. In G. H. Bower (Ed.), The psychology of learning \& motivation (Vol. 11, pp. 277-320). New York: Academic Press.

ERIKSEn, C. W., \& Colegate, R. L. (1971). Selective attention and serial processing in briefly presented visual displays. Perception \& Psychophysics, 10, 321-326.

ERIKSEN. C. W. \& HoffMAN. J. E. (1972). Temporal and spatial characteristics of selective encoding from visual displays. Perception \& Psychophysics, 12, 201-204.

ERIKSEN, C. W., \& ST. JAMES, J. D. (1986). Visual attention within and around the field of focal attention: A zoom lens model. Perception \& Psychophysics, 40, 225-240.

ERIKSEN, C. W., \& YEH, Y. Y, (1985). Allocation of attention in the visual field. Journal of Experimental Psychology: Human Perception \& Performance, 5, 583-595.

FolK, C. L., Remington, R. W., \& Johnston, J. C. (1992). Involuntary covert orienting is contingent on attentional control settings. Journal of Experimental Psychologv: Human Perception \& Performance, 18 , 1030-1044.

Folk, C. L., Remington, R. W., \& Wright, J. H. (1994). The structure of attentional control: Contingent attentional capture by apparent motion, abrupt onset, and color. Journal of Experimental Psychology: Human Perception \& Performance, 20, 317-329.

HaSher, L., \& ZaCks, R. T. (1979). Automatic and effortful processes in memory. Journal of Experimental Psychology: General, 108, 356388.

Hawkins, H. L., Shafto, M. G., \& Richardson, K. (1988). Effects of target luminance and cue validity on the latency of visual detection. Perception \& Psychophysics, 44, 484-492.

Henderson, J. M. (1991). Stimulus discrimination following covert attentional orienting to an exogenous cue. Journal of Experimental Psychology: Human Perception \& Performance, 17, $91-106$.

Henderson, J. M., \& Maceuistan, A. D. (1993). The spatial distribution of attention following an exogenous cue. Perception \& Psychophysics, 53, 221-230.

JoHNSON, D. N., \& YANTIS, S. (1995). Allocating visual attention: Tests of a two-process model. Journal of Experimental Psychology: Human Perception \& Performance, 21, 1376-1390.

JONIDES, J. (1981). Voluntary versus automatic control over the mind's eye's movement. In J. B. Long \& A. D. Baddeley (Eds.), Attention and performance $I X$ (pp. 187-203). Hillsdale, NJ: Erlbaum

Jonides, J., Naveh-Benjamin, M., \& Palmer, J. (1985). Assessing automaticity. Acta Psychologica, 60, 157-171.

JONIDES, J., \& YANTIS, S. (1988). Uniqueness of abrupt visual onset in capturing attention. Perception \& Psychophysics, 43, 346-354.

Kahneman, D., \& Treisman, A. (1984). Changing view of attention and automaticity. In R. Parasuraman \& D. A. Davies (Eds.), Varieties of attention (pp. 29-61). San Diego: Academic Press.

Kahneman, D., Treisman, A., \& Burkell, J. (1983). The cost of visual filtering. Journal of Experimental Psychology: Human Perception \& Performance, 9, $510-522$.

Kahneman, D., Treisman, A., \& Gibbs, B. J. (1992). The reviewing of object files: Object-specific integration of information. Cognitive Psychology, 24, 175-219.

KANWISHER, N., \& DRIVER, J. (1992). Objects, attributes, and visual attention: Which, what and where. Current Directions in Psychological Science, 1, 26-31.

Koshino, H., Warner, C. B., \& Juola, J. F. (1992). Relative effectiveness of central, peripheral, and abrupt-onset cues in visual attention. Quarterly Journal of Experimental Psychology, 45A, 609-631.

LABERGE, D. (1983). Spatial extent of attention to letters and words. Journal of Experimental Psychology: Human Perception \& Performance, 9, 371-379.

LABERGE, D., \& BRown, V. (1986). Variations in size of the visual field in which targets are presented: An attentional range effect. Perception \& Psychophysics, 40, 188-200.

LABERGE, D., \& Brown, V. (1989). Theory of attentional operations in shape identification. Psychological Review, 96, 101-124.

Maringelli, F., \& UmiLtà, C. (1998). The control of the attentional focus. European Journal of Cognitive Psychology, 10, 225-246.

Martin, D. W., \& BENSON, A. E. (1991, November). Is there a color advantage in visual search? Paper presented at the 32nd Annual Meeting of the Psychonomic Society, San Francisco.

MiLLER, J. (1989). The control of attention by abrupt visual onsets and offsets. Perception \& Psychophysics, 45, 567-571.

Mizuno, M., Umiltà, C., \& Sartori, G. (1998). Control of the attentional focus in chronic schizophrenics. Cortex, 34, 263-270.

Müller, H. J., \& Findlay, J. M. (1988). The effect of visual attention on peripheral discrimination thresholds in single and multiple element displays. Acta Psychologica, 69, 129-155.

Müller, H. J., \& RabBitt, P. M. A. (1989). Reflexive and voluntary orienting of visual attention: Time course of activation and resistance to interruption. Journal of Experimental Psychology: Human Perception \& Performance, 15, 315-330.

Petersen, S. E., Robinson, D. L., \& Morris, J. D. (1987). Contributions of the pulvinar to visual spatial attention. Neuropsychologia, 25, 97-105.

POSNER, M. I. (1978). Chronometric exploration of the mind. Hillsdale, NJ: Erlbaum.

PoSNER, M. I. (1980). Orienting of attention. Quarterly Journal of Experimental Psychology, 32, 3-25.

POSNER, M. I. (1988). Structures and functions of selective attention. In T. Boll \& B. Bryant (Eds.), Master lectures in clinical neuropsychology (pp. 173-202). Washington, DC: American Psychological Association.

POSNER, M. I., \& COHEN, Y. (1984). Components of visual orienting. In H. Bouma \& D. G. Bouwhuis (Eds.), Attention and Performance $X$ (pp. 531-556). Hillsdale, NJ: Erlbaum.

Posner, M. I., Nissen, M. J., \& Ogden, W. C. (1978). Attended and unattended processing modes: The role of set for spatial location. In H. L. Pick \& I. J. Saltzman (Eds.), Modes of perceiving and processing information (pp. 137-157). Hillsdale, NJ: Erlbaum.

Posner, M. I., \& Petersen, S. E. (1990). The attention system of the human brain. Annual Review of Neuroscience, 13, 25-42.

Posner, M. I., \& SNyder, C. R. R. (1975). Facilitation and inhibition in the processing of signals. In P. M. A. Rabbitt \& S. Dornic (Eds.), Attention and performance $V$ (pp. 669-682). New York: Academic Press. 
Posner, M. I., Snyder, C. R. R., \& Davidson, B. J. (1980). Attention and detection of signals. Journal of Experimental Psychology: General, 109, 160-174.

Posner, M. I., Walker, J. A, Friedrich, F. A., \& Rafal, R. D. (1987). How do the parietal lobes direct covert attention? Neuropsychologia, 25, 1135-145.

Riggio, L., \& KirSNER, K. (1997). The relationship between central cues and peripheral cues in covert visual orientation. Perception \& Psychophysics, 59, 885-899.

SCHNEIDER, W., \& SHIFFrin, R. M. (1977). Controlled and automatic human information processing: I. Detection, search, and attention. Psychological Review, 84, 1-66.

Sokolov, E. N. (1963). Perception and the conditioned reflex. Oxford: Oxford University Press, Pergamon Press.

STOFFer, T. H. (1991). Attentional focussing and spatial stimulusresponse compatibility. Psychological Research, 53, 127-135.

STOFFER, T. H., \& UMILTÀ, C. (1997). Spatial stimulus coding and the focus of attention in S-R compatibility and the Simon effect. In B. Hommel \& W. Prinz (Eds.), Theoretical issues in stimulusresponse compatibility (pp. 181-208). Amsterdam: Elsevier.

THEEUWES, J. (1991). Exogenous and endogenous control of attention: The effect of visual onsets and offsets. Perception \& Psychophysics, 49. 83-90.

Theeuwes, J. (1994). Stimulus-driven capture and attentional set: Selective search for color and visual abrupt onsets. Journal of Experimental Psychology: Human Perception \& Performance, 20, 799-806.

TODD, J. T., \& VAN GELDER, P. (1979). Implication of a transientsustained dichotomy for the measurement of human performance. Journal of Experimental Psychology: Human Perception \& Performance, 5, 625-638.

Treisman, A., Kahneman, D., \& Burkell, J. (1983). Perceptual objects and the cost of filtering. Perception \& Psychophysics, 33, 527 . 532.

Umiltà, C., Riggio, L., Dascola, I., \& Rizzolatti, G. (1991). Differential effects on central and peripheral cues on the orienting of spatial attention. European Journal of Cognitive Psychology, 3, 247-267.
VAN DER HeUdDen, A. H. C. (1992). Selective attention in vision. London: Routledge.

WARNER, C. B., JUOLA, J. F., \& Koshino, H. (1990). Voluntary allocation versus automatic capture of visual attention. Perception \& Psychophysics, 48, 243-251.

WundT, W. (1903). Physiologische Psychologie (5th ed., Vol. III). Leipzig: Engelmann.

YANTIS, S. (1993). Stimulus-driven attentional capture and attentional control settings. Journal of Experimental Psychology: Human Perception \& Performance, 19, 676-681.

Yantis, S., \& Hillstrom, A. P. (1994). Stimulus-driven attentional capture: Evidence from equiluminant visual objects. Journal of Experimental Psychology: Human Perception \& Performance, 20, 95 107.

YanTIS, S., \& Jonides, J. (1984). Abrupt visual onset and selective attention: Evidence from visual search. Journal of Experimental Psychology: Human Perception \& Performance, 10, 601-621.

YANTIS S., \& JONIDES, J. (1990). Abrupt visual onset and selective attention: Voluntary vs. automatic allocation. Journal of Experimental Psychology: Human Perception \& Performance, 16, 121-134.

\section{NOTES}

1. Saying that the processes (automatic and voluntary orienting) are simultaneously active does not imply that the two have identical onsets or time courses, but merely that the time courses of the processes (at least partially) overlap.

2. In Experiment 1, the center of the cue was an empty spatial dimension, whereas in Experiment 2, the fixation point was present. However, because it was very small $\left(0.1^{\circ}\right.$ of visual angle), it is very likely that the focus of attention could not have been fitted to it. In fact, LaBerge and Brown (1989) argued that the attentional focus cannot be smaller than about $0.2^{\circ}-0.4^{\circ}$.

(Manuscript received June 30, 1998; revision accepted for publication July 8,1999 .) 